\title{
Export Potential of Recycled Plastic: A Study on Bangladesh
}

\author{
Mehnaz Hossain ${ }^{1}, \&$ Aditi Shams ${ }^{1}$ \\ ${ }^{1}$ Department of International Business, University of Dhaka, Bangladesh \\ Correspondence: Aditi Shams, Department of International Business, University of Dhaka, Bangladesh. Tel: \\ 880-2366-1900. E-mail: aditishams@du.ac.bd
}

Received: December 26, 2019

doi:10.5539/ass.v16n3p12
Accepted: January 11, $2020 \quad$ Online Published: February 27, 2020

URL: https://doi.org/10.5539/ass.v16n3p12

\begin{abstract}
In the age of sustainable business practice, the usage of plastic is a matter of great concern. Bangladesh, being a developing country, has a huge amount of plastic waste. However, there is a dearth of empirical research that investigates the potential of recycled plastic industry development in Bangladesh. Therefore, the purpose of this study is to examine the external and internal factors affecting the recycled plastic industry of Bangladesh and to provide recommendations to develop the recycled plastic industry as a potential source of export. To this end, an exploratory study was conducted, and ten officials from Bangladesh based small-and-medium enterprises were interviewed. The results reveal that Bangladesh has huge potential for the recycled plastic industry operation. However, the industry lacks government and institutional support. If public and private sectors can come forward to promote the recycling sector, then this industry has the potential to be one of the most profitable industries in Bangladesh. Based on the expectations of the interviewees, some policy recommendations are suggested to develop the recycled plastic industry. Recommendations have highlighted effective and efficient waste management systems, proper planning, efficient technology usage, infrastructural development, the developed value chain for the collection of plastic wastes, among others. Most importantly, coordinated efforts of government, consumers, recycling industries, and plastic product manufacturers can contribute to the establishment of the plastic recycling sector as a major productive industry in Bangladesh.
\end{abstract}

Keywords: sustainable business, plastic, plastic waste, recycled plastic products, and recycled plastic industry

\section{Background and Motivation}

The purpose of this report is to identify how recycled plastic can be one of the potential export-oriented products in Bangladesh and can contribute to our economy as a profitable industry. The demand for plastic products over the world is increasing day by day because of its flexibility and low price. Plastic flakes which are made from recycled plastic are inexpensive to reproduce a different kind of products. Many countries have adopted different innovative ideas to reproduce new products and energy by using plastics wastes and have also started to export. Through export, these countries are contributing to their economy and becoming successful in protecting their environment from plastic pollution. It can be a great opportunity for Bangladesh if we can adopt the idea accurately. There are almost 300 plastic recycling companies in Dhaka, which produce plastic flakes and other plastic products by recycling. The existing export-based recycling factories of Bangladesh are exporting plastic flakes and other different kind of products such as PETE straps, PETE palettes, PETE shred to India, China, Thailand, Vietnam, Austria, Ukraine, Philippines, Taiwan and to some of European countries in a small range which are not meeting the demand of buyers. Instead of having a high demand for recycled plastic products in the international market, all factories in our country cannot produce export quality plastic flakes and other recycled plastic products. If the Bangladesh government concentrates on this sector, it can be one of the most profitable industries in Bangladesh.

Plastic came into existence in $19^{\text {th }}$ century. It became familiar only after 1950 s. From that period, scientists assume that almost 9.2 billion tons of plastic have been produced, and 6.9 billion tons have become waste, and 6.3 billion can never be recycled. The situation is destroying the life of the animal in sea dangerously, and there is no exact idea of how much plastics have been thrown into the sea. Because of plastic, our entire planet is now under threat. One million plastic bottles are purchased every minute globally. Most used plastic materials are non-biodegradable. Managing plastic waste is increasingly becoming a global environmental and economic challenge. Plastic waste is a risk to public health as it enters our food chain, creates congestion problems in drains, causing flooding, ends up in river beds and oceans, depleting ecosystems and marine biodiversity, makes 
solid waste management more expensive as landfills and open incineration do not provide an acceptable solution for disposal. There is only one way to develop new technologies for converting plastic into profitable substances through recycling.

"Recycling of Plastic" is a wonderful idea that can contribute to both the economy and the environment of any country. Bangladesh is an overpopulated country, and environmental pollution has become a threat to all existence. Plastic pollution is becoming a tremendous problem in this country because of its increasing use by all kinds of people. With increasing use, the volume of plastic wastes inside the country is also rising greatly. It is a matter of great concern that there is no enough procedure and technology through which plastic and other wastes can be reused to protect the environment from pollution. There are some small and medium companies in our country which only make plastic chips through the recycling process, but it is not enough to think recycled plastic as one of the potential export-oriented products which may contribute to our economy in the future. Many large industries purchase e-plastic chips from small-sized plastic recycling factories to reproduce new products, but they do not follow environmental law dispose of plastic wastes correctly.

Three major areas of Bangladesh, such as Dhaka, Chittagong, and Sylhet, are in great danger. A report has found that about 14 million pieces of poly-bags are being thrown out every day in Dhaka city. The report has also stated that Bangladesh experienced floods in urban areas in 1998 and 2008 where polythene and plastic materials were one of the major causes for the blockage of the drainage systems. A recent report published by Earth Day Network (2018) ranked Bangladesh 10th out of the top 20 plastic polluting countries in the world. Plastic contributes eight percent of the country's waste, which is equivalent to 800,000 tones, of which around 200,000 tones go into the ocean and rivers.

Bangladesh has a great opportunity to reuse its plastic wastes to foster both of economy and protect the environment from pollution because of the availability of a high volume of plastic wastes inside our country. Plastic wastes can be used to produce new products and energy. In Bangladesh, there are over three thousand small and big plastic companies. It is a growing industry. The recycled plastic industry contributes around 2 billion (BDT) to the Bangladesh GDP, employs around 1.2 million people, and is certified as 'Green Industries' according to ISO-2009 and ISO-2014 certification. These industries export worth 4 billion (BDT). Also, these plastic industries are producing many household products as well as many wooden products can be produced by plastic like plastic furniture. Nature can be restored by substituting wooden furniture with recyclable plastic materials. Many construction materials are also produced by using plastic (Islam, 2011). Hence Bangladesh will be beneficial if plastic wastes are used to produce diversified, which have high demand inside and outside of our country.

Plastic waste has become a blessing to many countries like Germany, Austria, South Korea, Netherlands, Italy, Sweden, Switzerland, and others because they use recycled plastic as a resource to produce new products. Many countries like China imported plastic wastes from developing nations a few years ago, but in 2018 China has banned importing plastic wastes and started to import plastic flakes. Besides, Sweden, Switzerland, and some developed countries import plastic wastes from other countries to produce energy, chemical, bitumen, and petroleum, along with new plastic products (Velis, 2014) Developing countries like Bangladesh and others are not eligible to adopt this process. Bangladesh is an overpopulated country with huge usage of plastic products. A study has shown that Bangladesh recycles almost $69 \%$ of its total plastic wastes, but the companies which are recycling it are not focusing on the issues as well as our government. Our export is highly dependent on readymade garments (RMG), which contributes about $80 \%$ of our export.

Plastic waste is harmful to the environment, but recycled plastic can be a profitable resource for a country. From this point of view, research on the potential of recycled plastic industry in Bangladesh and its export is eminent. But there is a dearth of research in this area. Therefore, this study focus on examining the potential of recycled plastic as a profitable industry and export-oriented recycled product in Bangladesh.

This exploratory research will focus on the following two issues:

1. To explore the potential of the plastic recycling sector as a profitable industry in Bangladesh.

2. To explore the potential of recycled plastic as an export-oriented product in Bangladesh.

2.

2.1 Why Plastics?

Plastics are inexpensive, lightweight, and durable materials, which can readily be molded into a variety of products that find use in a wide range of applications. As a consequence, the production of plastics has increased markedly over the last 60 years. However, current levels of their usage and disposal generate several 
environmental problems (Hopewell, Dvorak, \& Kosior, 2009). Plastic products are very useful for every household all over the world. This sector is flourishing day by day. It is contributing to the global economy in general. Earlier, the wastes of plastic products were harmful to human health and the environment. Currently, many countries are turning wastes into resources through recycling (Sultana, 2019). According to the OECD report, the widespread use of plastics has generated several benefits for society and the environment. Plastics are often used to protect or preserve foodstuffs and, in doing so, help to reduce food waste. Plastics are also an important input in vehicles and limit fuel use and greenhouse gas emissions. Plastics are widely used in infrastructure applications, where their impermeability and durability can lead to water savings in urban areas. Also, the use of plastics rather than materials derived from biomass (e.g., wood and paper) in a range of applications could slow land-cover change and biodiversity loss.

\subsection{Plastic Wastes and Environment}

The increasing pervasiveness of plastics has not been without drawbacks. The production and disposal of plastics are responsible for significant greenhouse gas emissions and, when poorly managed, generate plastics pollution in the natural environment (Ritche \& Roser, 2018). The theme of "World Environment Day 2018" was "Beat Plastic Pollution," which has invited all governments, communities, and individuals of all countries to come together and work together to reduce plastic pollution. It has emphasized the major issues such as reduction of plastic pollution, reuse, and recycles of used plastic and also moves to the other alternatives to plastic Plastic is a dangerous toxic and perilous threat to existence (Sultana, 2019). The plastic-derived products, nowadays, become an indispensable commodity for different purposes. A huge amount of used plastic causes environmental hazards that turn in danger for marine life, reduces the fertility of the soil, and contamination of groundwater. Management of this enormous plastic waste is challenging in particular for developing countries like Bangladesh Lack of facilities, infrastructure development, and insufficient budget for waste management are some of the main reasons of improper plastic management in Bangladesh.

\subsection{The Growth of Plastic Production and Plastic Wastes around the World}

In 1950 the world produced only 2 million tons of plastic per year. Since then, annual production has increased nearly 200-fold, reaching 381 million tons in 2015. For context, this is roughly equivalent to the mass of two-thirds of the world population (Leblance, 2019). By 2015, the world had produced 7.8 billion tonnes of plastic, more than one tonnes of plastic for every person alive today (Ritche \& Roser, 2018). Since 1950, plastics have rapidly become one of the most commonplace materials on the planet. In 2015, global plastics production reached 407 million tonnes per annum (Mtpa), making it more than the production of paper (400 Mtpa), fish (200 Mtpa), and aluminum (57 Mtpa). If production continues to grow at similar rates, plastics production will reach 1600 Mtpa in 2050 (OECD Report, 2018).

\subsection{Plastic Recycling and Trade of Plastic Wastes}

Recycling means the reprocessing and re-fabricating of a material that has been used and discarded by a consumer and that otherwise would be destined as solid waste. This recycle is called post-consumer recycling, as opposed to recycling, which is created as a normal part of scrap from a manufacturing process. The reprocessing of plastic materials into useful products needs several steps, such as collection, sorting, cleaning, and re-fabricating (Shimo, 2014). Recycling operations depend profoundly on production and consumption. A shift in plastics production from the West to Asia has occurred: $40 \%$ by weight of world production is now in Asia, with $20 \%$ each in Europe and North America. China is the largest individual country, at 24\% (OECD Report, 2018).

Plastic trade waste is limited and increasingly hindered by trade restrictions. But this flow can help to boost global recycling rates, while also generating increased shared economic benefits and improving environmental outcomes. Despite that, global trade in plastics waste remains small relative to overall plastics waste generation. Of the 300 million tonnes of plastics waste generated in 2015, only around 14 million tonnes (or 4\%) was exported outside the country of origin (OECD Report, 2018).

\subsection{Export and Consumption rate of Plastic Products by Bangladesh}

According to the Export Promotion Bureau (EPB) of Bangladesh, a growth rate of 30.07 percent, with net export earnings of USD 48.75 million, was achieved in FY2018-19 (July-November) compared to USD 37.48 million in FY2017-18 (July-November). Plastic flakes are important raw materials to produce a different kinds of plastic products. The plastic industry uses imported raw materials of polymer granules, and there is no enough production of polymers in Bangladesh (Islam, 2011). In 2013, in a TV interview, the president of PET flakes exporter association told that around 500,000 metric tons per year of flakes had been exported, and they earn 
around 1500-2000 million dollars in a year (Sultana, 2019). The consumption of plastic per capita is 5 K.G in Bangladesh, where the average consumption of the world is $30 \mathrm{~kg}$ per capita (Islam, 2011). That shows a huge demand for plastic inside and outside of the country.

\subsection{The Demand for Products made from Recycled Plastic}

The top world importers of plastic waste are Hong Kong USA, Netherlands, and Belgium (Velis, 2014). India started taking plastic flakes from Bangladesh, which is made from recycling plastic waste, in earlier China used to take from Bangladesh. PET is used as a raw material for making packaging materials such as bottles and containers for packaging a wide range of food products and other consumer goods which have a great demand in the world.

\subsection{The Potential of Plastic Recycling in Bangladesh}

The plastic recycling companies in Bangladesh don't make any products with recycled plastic flakes. They only export the flakes. So it will be a good opportunity to start an industry only for the recycled plastic flakes (Sultana, 2019). A study found that there are some companies that are directly involved with plastic recycling, but they recycle only PET bottles, and they export the chips (flakes and scrap) to China.

China was the prime plastic manufacturing country in the world. China used to import plastic wastes from Bangladesh for further processing, but it has stopped doing so. The country is closing down plastic waste processing plants because of environmental pollution. As it has started moving towards high-tech industries, there's a massive opportunity for Bangladeshi exporters to increase the global market share (Ahmed, 2018). Although the plastic industry in Bangladesh has made remarkable progress over the years still they need a well-designed plan to be more reliable to the consumers (Shimo, 2014). Because of the low costs, a plastic recycling factory could be quite rewarding to start in Bangladesh (Sultana, 2019).

\subsection{Challenges of Plastic Recycling}

A study has shown that, management of plastic waste is challenging in particular for developing countries like Bangladesh. Lack of facilities, infrastructure development, and insufficient budget for waste management are some of the prime causes of improper plastic management in Bangladesh. Like other developing countries, plastic waste recycling is inadequate in this country. The situation of recycling in the country is a grim reflection of the extent of environmental hazards caused by the plastic industry all over Bangladesh. Though the Government of Bangladesh is providing tax exemption on account of recycling companies are not concerned about the proper recycling procedure (Sultana, 2019, p. 3).

3.

\subsection{Plastic Waste Generation by Bangladesh}

According to the Department of Environment (DOE) of Bangladesh, Bangladesh imports plastic raw materials worth 2000 core which can be produced by recycling the plastic wastes in-country. Bangladesh generates 1700 tonnes of plastics wastes every day and only half of which is being recycled. Around 3 lakh tonnes of plastic wastes are dumped in the open. One reason why recycling proved to be inefficient in Bangladesh is that the wastes is not dumped in an organized way. Different types of plastic products are often dumped together at the same place, thus making it difficult and time-consuming to sort the different types of plastic products and starting the recycling process (Ayan, 2018). This often raises the cost of operation too, that creates few interests among the people to start this business.

\subsection{Plastic Waste Recycling Companies in Bangladesh}

There are almost 300 plastic recycling factories in Dhaka. Daily sale of each factory is 2-3 lakh takas, and the monthly sale of these factories is about 2.70 billion (BDT). Though there is no institutional backup the total contribution to the economy of Bangladesh from this sector was almost 280 billion (BDT) in 2016. This economic status provides a brief overview of the potential of recycled plastic industry.

\subsection{Recycling of Plastic Wastes}

There are different kinds of plastic wastes, all of which cannot be recycled. The number and level in the recycling symbol give the idea of which plastic wastes can be recycled and which cannot be. The picture of different recycling symbol is given below; 


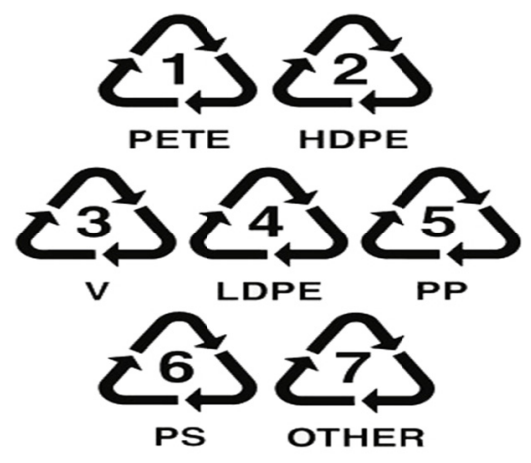

Figure 1. Recycling Symbol

Plastic recycling factories of Bangladesh use only PETE to make plastic flakes, which have huge demand in India, China, Vietnam, Thailand, South Korea, Taiwan, Philippines, Europe, and Ukraine. If the companies can reuse the other wastes, then it would be a great opportunity for Bangladesh to establish recycled plastic as a potential export-oriented industry. But the main barriers in our country are lack of technology and proper waste management system (Ahmed, 2019).

\subsection{Plastic Recycling Procedure in Bangladesh}

Earlier plastic waste became a problem for the health of humans, animals, and sea creatures. Now plastic recycling can reverse the adverse effect. Recycling is a process of turning wastes into resources. It helps to preserve natural resources to prevent pollution. There are five phases of the plastic recycling process in our country, e.g. collecting, sorting, cleaning and drying, shredding, pelletizing.

\subsection{Products made of Recycled Plastics}

The number within the recycling symbol on plastic containers provides a wealth of information about their safety, biodegradability, and recyclability. But Bangladesh only uses PET plastics to produce plastics flakes through recycling whereas it has a lot of scopes to produce diversified products. Recycled plastic can be a separate profitable industry for Bangladesh. Table 1 provides an overview of the lists of products that can be produced from recycled plastics.

Table 1. Products Made from Recycled Plastic

\begin{tabular}{ll}
\hline Types of plastic wastes & Products made through recycling \\
\hline PETE or PET (Polyethylene Terephthalate) & Carpet, Furniture, Resins, and Fiber for winter garments. \\
HDPE (High-Density Polyethylene) & Pens, Plastic lumber, Plastic Fencing, Picnic tables, and Bottles. \\
PVC (Polyvinyl Chloride) & Flooring, Paneling, and Roadside Gutters \\
LDPE (Low-Density Polyethylene) & Garbage cans, Paneling, Furniture, Flooring and Bubble wrap \\
PP (Polypropylene) & Pallets, Ice scrapers, Rakes and Battery cables \\
PS (Polystyrene) & PS is recycled into various items including insulation, school \\
& supplies, and license plate framing. \\
\hline
\end{tabular}

Source: Hossain (2016).

\subsection{Demand of Plastic Products in Bangladesh}

Bangladesh is a middle-income country, and people always search for low priced and flexible goods for their daily use. Plastic products are cheap and flexible and therefore have a huge demand in Bangladesh. With the increase in demand for plastic products, the size of plastic industries is increasing in Bangladesh. Table 2 provides a timeline of the increased use of plastic products in Bangladesh from year 1960 to 2010.

Table 2. Use of Plastic Products

\begin{tabular}{ll}
\hline Year & Technology and Products \\
\hline 1960 's & $\begin{array}{l}\text { Small products such as toys, bangles and photo frame where made using handmade molds. Plastic } \\
\text { spare parts for jute mills }\end{array}$ \\
1970's & Automatic machines were installed to manufacture household utensils such as plastic jugs and plate \\
\hline
\end{tabular}


1980's Film blowing machines to manufacture plastic bags

1990's Plastic accessories especially hangers for exportable garments

2000's Molded plastic chairs and tables. Water tank made by rotation molding. Locally developed machines (shredder, extruder, and pelletize) for recycling plastic wastes.

2010's Now-a-days there are about 3000 plastic factories in the country. Out of them 1968 factories are small, 980 are medium and the rest 52 are large companies which deal internationally.

Source: Sultana (2019)

\subsection{Potential of Recycled Plastic Products in Bangladesh}

Plastic products were introduced in Bangladesh, in the latter half of the 1940s. Significant growth in the plastics sector took place during the last two decades after the introduction of the free market in the 1990's. At present, there are about 5,000 plastic industries in the country, of which 3,500 are small, and 1,480 are medium \& 20 are large sized. The plastics recycling subsector, composed of around 300 small units in Dhaka employing 25,000 workers, produces recycled products out of about 140 tons/day of plastic waste (Ahmed, 2019) Plastic recycling has also developed into a sizeable component of the plastics industry with major recycling centers in and around Dhaka. The availability of river water (used in cleaning) and low transportation costs have made recycling units located around Dhaka economically attractive. Recycling of plastic wastes saves import costs for the industry and helps to improve overall waste management situations. So the friendly environment of Bangladesh and the availability of all the factors of production for recycling prove that Bangladesh has a great opportunity to foster this potential area. Recycled plastic can be an important industry, and it is now also a growing sector of Bangladesh. So it can be said that the potentiality of recycled plastic in Bangladesh is enormous.

\subsection{Bangladesh Can Follow Other Countries to Utilize Recycled Plastic}

Bangladesh can use recycled products to diversified by-products using plastic wastes. But Bangladesh faces some pivotal problems, such as, lack of efficiency, knowledge, experience and high technology which are lagging us behind the other countries in the plastic recycling sector. It high is time that Bangladesh gathers the knowledge and skill to get rid of plastic wastes. The following initiatives that proved to be profitable in some countries can be replicated in Bangladesh as well.

1. The most profitable way to turn plastic wastes into resources is by turning plastics to oil by thermal cracking, which is a chemical process. Plastics are mainly petroleum-based polymers, which means, in the basic form, it is petroleum products. Any plastic wastes can be turned back to petroleum under conditions of certain temperature and pressure. The petroleum produced is in an amalgamated liquid form, which can then be separated into different products with specific uses. Bangladesh can follow this process to produce petroleum by recycling (Ayan, 2018).

2. Sweden and Germany, the two countries which are recycling wastes, especially plastic wastes most efficiently, are using their wastes for incineration, but in a process that will generate energy. The process, namely waste-to-energy, is quite a profitable one and is capable of producing energy in the form of electricity in quite the same way as a thermal power plant works, only using plastics instead of fossil fuel in this case. Since Bangladesh has a huge demand for electricity in the country, we may consider burning the wastes to produce power to run the industries and factories, thus allowing them cheaper electricity and enabling them to flourish (Ayan, 2018).

3. In India, for example, bitumen, made from plastic wastes, is used for roads and highways construction. Bangladesh is going through huge infrastructural development for which it can make use of recycled plastics (Ayan, 2018).

4. In UK, petroleum-based liquid, named Plax is produced using innovative recycling technologies Plax is further used to produce naphtha substitute/light oil (Plaxx-8), low sulphur heavy fuel oil (Plaxx-16), base oil (Plaxx-30), and wax (Plaxx-50) (Ayan, 2018).

5. China, on the other hand, is producing thread and winter garment materials by using plastic flakes which are mainly imported from India and Bangladesh (Ayan, 2018). 
4.

\subsection{Research Design}

The objective of discovering the potentiality of recycled plastic as a profitable industry and export-oriented product in Bangladesh is required to know Businessmen's experience, including manufacturers, suppliers, and exporters in this area from their business perspective, which led to the choice of qualitative method. A descriptive research design has been taken for analysis. Semi-structured in-depth face-to-face interviews were utilized to understand the world from the subjects' point of view (Brinkmann \& Kvale, 2015).

\subsection{Number of Interviewees}

A group of 10 people who are the owners, managers, and supervisors of 10 different small and medium-sized plastic recycling factories engaged in this sector for a minimum of 3 years were interviewed. The small and medium plastic recycling factories are mostly situated in Chackbazar, Lalbagh, and Kamrangirchor. Having no set guideline for sample size in qualitative studies, a topic left to the judgment of the researcher (Crewshell, 2014). The interviewing process was continued with 10 mill's owners until the point of data saturation was perceived to be reached. Each interview lasted from 30 to 45 minutes.

\subsection{Data Collection}

The interview and documentation process has been used to collect data. A semi-structured and open-ended questionnaire is prepared. The questions were related to the production potentiality, production cost, availability of labor forces and raw materials, technology inefficiency, and other factors. The questions also include the opportunities in the domestic and international markets, and threats come from the uncontrollable external factors. The information about different factors that influence recycling plastic operation in Bangladesh in terms of political, environmental, social, technological, economic, and legal have been also collected. In addition, the respondents were asked about their expectations from the government to make recycled plastic one of the export-based products.

List of Interviewees:

\begin{tabular}{cccc}
\hline No. & Name of Mills & Place of the factory & Position of interviewees \\
\hline 1. & Khaja Engineering Works & Chackbazar, Dhaka & Proprietor \\
2. & Ashiki Rosul Plastic Factory & Kamrangirchor, Dhaka & Proprietor \\
3. & Jannat Enterprise & Lalbagh, Dhaka & Manager \\
4. & Rohmot Ali Enterprise & Chackbazar, Dhaka & Proprietor \\
5. & Bismillah Plastic Recycling Factory & Lalbagh, Dhaka & Manager \\
6. & Nurjahan PET Mills & Kamrangirchor, Dhaka & Mill Supervisor \\
7. & Kabir Traders Pvt. Ltd & Lalbagh, Dhaka & Manager \\
8. & H\&H Association & Chackbazar, Dhaka & Proprietor \\
9. & Nahid Plastic Enterprise & Lalbagh, Dhaka & Proprietor \\
10. & MSA Enterprise & Kamrangirchor & Supervisor \\
\hline
\end{tabular}

\subsection{Data Analysis}

The collected information from primary and secondary sources are utilized and categorized based on the purpose of this study. To analysis the potentiality of the recycled plastic industry, we have pursued an environmental scanning technique where the external and internal factors of the plastic recycling industry have been explored in the context of Bangladesh.

\section{Results}

\subsection{External Factors}

Analysis of external factors provides greater insights in understanding the export potential of the recycled plastic industry in Bangladesh, it is important to analyze the external factors. Companies within an industry have no control over their external factors. External factors can be classified into two areas including Micro Factors and Macro Factors. Micro factors consist of customers, suppliers, competitors, marketing, and other related areas. On the other hand, "Macro Factors" consist of Political, Economical, Social, Technological, Environmental, and 
Legal, which together stand for PESTEL. "PESTEL" is a strategic tool that is helpful to understand the growing opportunity, potentiality, direction, and threats of an industry. In this study, we have explored both micro and macro factors to understand the potentiality of the recycled plastic industry in Bangladesh.

Table 3. Micro-Level External Factors

\begin{tabular}{cll}
\hline \multirow{3}{*}{ Micro Environmental Factors } & Suptomers/Buyers & $\begin{array}{l}\text { 1. High Demand in International Market. } \\
\text { 2. Increasing Bargaining Power of Buyer. }\end{array}$ \\
\cline { 2 - 3 } & \multirow{2}{*}{ Competitors } & $\begin{array}{l}\text { 1. Availability of suppliers. } \\
\text { 2. Low Bargaining Power of Supplier. }\end{array}$ \\
\cline { 2 - 3 } & 2. Difficulty in Achieving Competitive Advantages. \\
\hline
\end{tabular}

\subsubsection{Customers and Buyers}

i. Customers/Buyers High Demand in International Market

The demand for plastic flakes in international market is very high. China is the largest buyer of plastic wastes from Bangladesh. The demand of China is about 25000 to 50000 metric tons per year, whereas cumulatively, all producers of Bangladesh can only meet 6500 to 7000 metric tons per year. But because of some dishonest people, Bangladesh has lost many Chinese buyers. Now India is the largest market of Bangladesh plastic flakes. Without that, Vietnam, Philippines, Thailand, Taiwan, Austria, Ukraine, and other European countries are showing interest in purchasing plastic flakes, shreds, and straps from our country. It is a great opportunity for us to foster this industry.

ii. Growing Bargaining Power of Buyer and Suppliers:

Because of having other alternatives, the bargaining power of foreign buyers is increasing. On the other hand, the existing plastic recycling companies in Bangladesh are highly competitive, which is called a perfectly competitive market. As it is known to us in perfect competition market, the bargaining power of buyers is relatively high, and, producers make very little or zero profit.

\subsubsection{Suppliers of Inputs}

\section{i. Availability of Suppliers:}

Huge consumption of plastic products and the low price of plastic wastes makes the raw material easily accessible for suppliers.

\section{ii. Low Bargaining Power:}

In the case of plastic wastes, the bargaining power of suppliers is very low in our country because of having huge alternatives available to producers. Sometimes recycling factories directly collect wastes from "Tokai" and "Vangari-Oyala."

\subsubsection{Competitors}

\section{i. Increasing International Competitors}

The number of international competitors is increasing day by day. They are coming with high inventions, technology, and knowledge. For example, India, is using fast-track innovative technologies to recycle plastic wastes and using it to produce varied products. However, in Bangladesh, lack of technology, poor infrastructure, lack of knowledge, skill, and innovation is a huge constraint to become successful in producing diversified products with recycled plastic wastes. Whereas other countries like India, China, UK, and Vietnam is using recycled plastic wastes to produce diversified products, Bangladesh only concentrates on plastic flakes. India is making plastic recycling machinery through efficient use of its capacity and resources. On the other hand, Bangladesh is importing these machineries from India, which is increasing the cost of producing plastic flakes. Without machinery, Bangladesh also has to import different kinds of chemicals from other countries for plastic flakes production. All those things are raising our cost, creating barriers for expansion of the industry.

ii. Difficulty in Achieving Competitive Advantage 
Rising prices of energy and other utilities have increased the recycling and production cost. Besides, the lack of skilled workers, lack of talent, and inefficient marketing techniques have increased difficulty in achieving a competitive position in the international market compared to other rivals.

\subsubsection{Marketing and Media}

Bangladesh does not employ any effective marketing and negotiation strategies to promote the potentiality of plastic recycling sectors for foreign investment as well as to promote recycled plastic products in the international market where it is very important to attract a foreign buyer. Bangladesh Plastic Goods Manufacturers and Exporters Association (BPGMEA) can take necessary steps to promote the potentiality of the recycled plastic industry of Bangladesh so that Bangladesh has a new industrial revolution. It can also be promoted as a "Waste Management" issue and can be a part of "Sustainable Development Goal 2030," which has been taken by the honorable Prime Minister.

Table 4. Macro-Level External Factors

\begin{tabular}{|c|c|c|}
\hline \multirow{16}{*}{$\begin{array}{c}\text { Macro Environmental } \\
\text { Factors }\end{array}$} & & Tax Policy. \\
\hline & Political (P) & Political Stability. \\
\hline & & Government Policy. \\
\hline & \multirow{4}{*}{ Economical (E) } & Economic Growth. \\
\hline & & Interest Rate on Bank Loan. \\
\hline & & Job Growth. \\
\hline & & Inflation Rate. \\
\hline & \multirow{2}{*}{ Social (S) } & Beneficial to the Entire Society. \\
\hline & & Living Standard. \\
\hline & \multirow{3}{*}{ Technological (T) } & Pace of Technological Development. \\
\hline & & Facilities of Research and Development. \\
\hline & & Technological Incentives. \\
\hline & Environmental (E) & Environmental Protection. \\
\hline & \multirow{3}{*}{ Legal (L) } & Legal Complexity. \\
\hline & & Health and Safety Law, \\
\hline & & Labor Law and Environmental Law. \\
\hline
\end{tabular}

\subsubsection{Political Factors}

The existing political factors are supportive of the establishment of recycled plastic as an industry in Bangladesh. These factors include tax policy, political stability, government policies, and other issues that influence the political climate of a country. They are mainly related to how the government takes initiatives and proper policies to promote and establish any industry. Bangladesh's government provides a $10 \%$ tax incentive to the exporter of recycled plastic on their total export, but it is not enough to promote the recycled plastic industry and requires more support from the public and private sectors. By analyzing political factors, we have got the following result;

Table 5. Political Factors

\begin{tabular}{ccl}
\hline $\begin{array}{c}\text { Area of } \\
\text { Interest }\end{array}$ & Status & \multicolumn{1}{c}{ Comments } \\
\hline Tax Policy & $\begin{array}{c}\text { Supportive for } \\
\text { exporters } \\
\text { Political }\end{array}$ & $\begin{array}{c}\text { Stable political } \\
\text { environment } \\
\text { exporters to engage in the plastic recycling business. }\end{array}$ \\
$\begin{array}{c}\text { The political condition of Bangladesh is stable enough to support any } \\
\text { business. }\end{array}$ \\
$\begin{array}{c}\text { Supportive for } \\
\text { Government } \\
\text { Policy }\end{array}$ & $\begin{array}{l}\text { From the viewpoint of owners of the plastic recycling factories, } \\
\text { operation }\end{array}$ & government policies are supportive of their business operation.
\end{tabular}


Sustainable

Development
Waste management can be a part of "Sustainable Development Goal 2030" where through the recycling process, the Bangladesh government can manage plastic wastes. Because waste management is related to health issues and $8 \%$ of the total wastes of our country contains plastics wastes.

\subsubsection{Economical Factors}

The present economic condition of our country supports to establish a new industrial era. Economic factors include economic growth, interest rate, exchange rate, inflation rate, and other factors related to the economic climate. All of those factors affect the production and export situation of any industry. Though the export environment in Bangladesh is highly supportive for investors, the high-interest rate on loans, increasing inflation rate, and other measures are creating a different kind of problems in industrial development. The findings that we get through our analysis regarding how economic factors impact the recycled plastic industry is given below;

Table 6. Economic Factors

\begin{tabular}{|c|c|c|}
\hline Area of Interest & Status & Comment \\
\hline Economic Condition & Supportive & $\begin{array}{l}\text { The present economic condition of Bangladesh } \\
\text { supports new industrial development. }\end{array}$ \\
\hline Interest Rate on Bank Loan & Interest rate is high & $\begin{array}{l}\text { High-interest rate on the bank loans discourages } \\
\text { entrepreneurs to invest in a new sector. }\end{array}$ \\
\hline Employment Opportunity & $\begin{array}{l}\text { High contribution } \\
\text { to creating new job } \\
\text { opportunity }\end{array}$ & $\begin{array}{l}\text { New industries or sectors contribute to creating } \\
\text { employment opportunities within a country that } \\
\text { supports the economic development of a country. }\end{array}$ \\
\hline Inflation Rate & $\begin{array}{l}\text { The high inflation } \\
\text { rate can have a } \\
\text { negative impact }\end{array}$ & $\begin{array}{l}\text { The high inflation rate can increase the price of used } \\
\text { plastics and chemicals which are needed to import } \\
\text { from other countries. }\end{array}$ \\
\hline
\end{tabular}

\subsubsection{Social Factors}

Social factors include the societal values, attitudes, cultural factors, and lifestyle that impact business as well as demographic factors such as population size, growth rate, and age distribution. The recycling plastic industry will be socially beneficial to all classes of people in any country. People throw their wastes on the road or dustbin and plastic wastes litter on the streets and bind the water removal system in the drain, which causes mosquitoes and flies. If plastics wastes are recycled, then these wastes will be managed properly, and people will be beneficial. The following result which we get through our analysis, reveals that the social factors have a positive impact on promoting recycling plastic industry in Bangladesh;

Table 7. Social Factors

\begin{tabular}{|c|c|c|}
\hline Area of Interest & Status & Comments \\
\hline $\begin{array}{l}\text { Beneficial to the entire } \\
\text { society }\end{array}$ & $\begin{array}{l}\text { The positive attitude } \\
\text { of the whole society } \\
\text { to the recycled plastic } \\
\text { industry }\end{array}$ & $\begin{array}{l}\text { All class of people of Bangladesh use plastic materials } \\
\text { in their regular tasks and generate a large volume of } \\
\text { plastic wastes. Plastic wastes are non-biodegradable } \\
\text { products, and it needs a proper disposition to protect the } \\
\text { environment, which is possible through recycling. So } \\
\text { the recycled plastic industry can be proved as a socially } \\
\text { beneficial industry of Bangladesh. }\end{array}$ \\
\hline Living Standard & $\begin{array}{l}\text { By creating a new } \\
\text { scope of work, the } \\
\text { plastics recycling } \\
\text { sector is contributing } \\
\text { to building a good } \\
\text { living standard of } \\
\text { people. }\end{array}$ & $\begin{array}{l}\text { Almost } 300 \text { small, medium, and large-sized plastic } \\
\text { factories have created job opportunities for thousands of } \\
\text { people. If the factories get institutional support from the } \\
\text { government then it will be able to create more } \\
\text { employment opportunities for the people. }\end{array}$ \\
\hline
\end{tabular}




\subsubsection{Technological Factors}

Technologically Bangladesh is lagging behind many neighborhood countries. To establish recycled plastic as a profitable and export-oriented industry in Bangladesh, it requires high technological investment from the public and private sectors. Technological factors include technological aspects like research and development activity, technological developments, technology incentives, and the pace of technological change. Through technological progress, it will be easy to get production efficiency by maintaining the proper quality and performance of products. It can also help to increase the export of recycled plastic products. The current situation of the technological arena of recycling plastic companies is very poor. Inefficient technology, poor infrastructure, and lack of high technological machinery have created a lot of barriers for exporters of plastic recycling companies in Bangladesh. China was a large buyer of recycled plastic flakes of Bangladesh, but because of low quality, the Chinese buyers are moving toward India. So it is time for the government of Bangladesh to take necessary steps to foster the flourishing sector and promote it as an industry. The findings regarding the impact of technological factors on plastic recycling sector are given below:

Table 8. Technological Factors

\begin{tabular}{ccl}
\hline Area of Interest & Status & \multicolumn{1}{c}{ Comments } \\
\hline $\begin{array}{c}\text { The pace of Technological } \\
\text { Development }\end{array}$ & $\begin{array}{c}\text { Very poor to } \\
\text { keep pace with } \\
\text { international } \\
\text { competitors }\end{array}$ & $\begin{array}{l}\text { The existing recycling factories only use cutter and washer } \\
\text { machines. Some companies have dryer machines, but the } \\
\text { majority uses sunlight to dry the plastic flakes. Because of } \\
\text { inefficiency in technologies, factories are unable to keep pace } \\
\text { with international producers }\end{array}$ \\
$\begin{array}{c}\text { The facility of Research and } \\
\text { Development in Recycling } \\
\text { Companies }\end{array}$ & $\begin{array}{c}\text { Absence of the } \\
\text { R\&D } \\
\text { department }\end{array}$ & $\begin{array}{l}\text { Even in large factories, there is no opportunity for research } \\
\text { and development to improve the quality of the existing } \\
\text { product or to develop new products. } \\
\text { Thechnological Supports }\end{array}$ \\
No support & $\begin{array}{l}\text { There is nochnological support from the public and private } \\
\text { sectors. }\end{array}$ \\
\hline
\end{tabular}

\subsubsection{Environmental Factors}

Plastic is a non-biodegradable toxic element that is greatly dangerous to health and the environment. The lands of Bangladesh are losing their fertility due to non-biodegradable wastes. If plastic wastes are systematically recycled, than it will no longer be harmful to the environment. When plastic is recycled, less plastic ends up in landfills, and thus, less of this material takes up room in our environment for hundreds of years. But in reality, recycling plastic companies are not free from drawbacks. Small and medium-sized recycling companies located in Islambagh and Kamrangirchor dump their plastic wastes, which cannot be recycled and need high technology and proper procedure to manage, that are not available to them. For this reason, the Buriganga River and its sides are being blocked by unclean plastic wastes. The government should focus on this issue and need to take necessary initiatives to make plastic recycling as a complete weapon to protect the environment from pollution. Table 9 lists the environmental impact of plastic recycled companies in Bangladesh.

Table 9. Environmental Factors

\begin{tabular}{ccc}
\hline Area of Interest & Status & Comment \\
\hline $\begin{array}{c}\text { Contributing to Protect the } \\
\text { Environment }\end{array}$ & Yes & $\begin{array}{r}\text { By recycling of plastic wastes, recycled plastic industry can } \\
\text { contribute to protect environment largely. }\end{array}$ \\
$\begin{array}{c}\text { Recycling factories have } \\
\text { their own dumping } \\
\text { procedure. }\end{array}$ & No & $\begin{array}{c}\text { Even if recycled plastic industry can contribute to dispose plastic } \\
\text { wastes but it must have own correct dumping procedure. Existing } \\
\text { plastic recycling companies have no their own waste management } \\
\text { system where these companies are polluting riverside by throwing } \\
\text { their own wastes. }\end{array}$ \\
\hline
\end{tabular}

\subsubsection{Legal Factors}

Bangladesh is an export-friendly country. Legal compliance for exporters in Bangladesh is low. The factors related to legal issues are labor law, consumer law, occupational health and safety regulation, and other industry-specific laws. To start recycling plastic factories in a small scope, investors only need a trade license, 
but when they want to export their plastic flakes to other countries, they need a dean certificate, ERC (Export Registration Certificate), and membership certificate of a business association along with trade license. By visiting some recycling factories, it has been observed that the existing recycling factories do not pay much attention to the labor law or occupational safety law, which indicates that they have no pressure to comply with law and regulation. Besides, to start a small-sized recycling factory which does not export directly, only requires a trade license. So it is clear that there is no complex legal binding or regulations which will pledge plastic recycling operation. The legal procedure to start a recycling business is simple in our country, which encourages investors to invest in this sector. Table 10 lists the legal issues related to recycled plastic industries.

Table 10. Legal Factors

\begin{tabular}{|c|c|c|}
\hline Area of Interest & Status & Comments \\
\hline Legal complexity & $\begin{array}{l}\text { Legal } \\
\text { complexity } \\
\text { is low }\end{array}$ & $\begin{array}{l}\text { Needs a trade license when entrepreneurs are not involved with } \\
\text { exporters. When they want to export, they require ERC, Dean } \\
\text { Certificate, and membership certificate of any business } \\
\text { associations. }\end{array}$ \\
\hline $\begin{array}{l}\text { Compliance with } \\
\text { occupational health and } \\
\text { safety law, labor law, } \\
\text { environmental law }\end{array}$ & Low liability & $\begin{array}{l}\text { By visiting different factories, it has been observed that the } \\
\text { factories have no good working environment and no proper } \\
\text { waste management system, which indicates they are not } \\
\text { conscious and liable to follow labor, environmental and safety } \\
\text { law. }\end{array}$ \\
\hline
\end{tabular}

\subsection{Internal Factors}

Internal factors refer to the company's internal strengths and weaknesses, which are related to production, resources, employee skill, capabilities and core competencies, research and development, working environment, and so on. All these factors have a large impact on the establishment of this industry and can build a competitive position in the domestic and international markets. Table 11 provides a list of the elements of the internal factors.

Table 11. Internal Factors

\begin{tabular}{cc}
\hline Elements of Internal Factors & Dimensions \\
\hline 1. Production and Operation & 1.1 High Production Potentiality \\
2. Resources & 1. 2. Low transportation cost \\
& 2.1. Availability of raw materials \\
3. Employee Skills and Mix & 2.2. Availability of Large and Cheap Labor Forces \\
& 3.1. Lack of knowledge and skill \\
4. Capabilities and Core Competencies & 4.2. Inefficient labor force and high turnover \\
& 4.1. Good Quality \\
5. Research and Development & 5.1. Lack of research \\
6. Others & 5.2. Lack of high technology \\
\end{tabular}

\subsubsection{Production and Operation}

i. High Production Potentiality:

The production of recycled plastic products has high potentiality in Bangladesh. It can be $100 \%$ export-oriented product. Till 2019 many small and medium recycling companies have been established in our country. The plastics recycling subsector, composed of around 300 small units in Dhaka employing almost 25,000 workers, produces recycled products out of about 140 tons/day of plastic waste. The number of plastic recycling factories 
is increasing rapidly. Investors are getting benefits and showing more interest to invest in this sector. Though all factories cannot export directly but many companies as suppliers or intermediary purchase plastic flakes from small sized factories and export it to other countries by further rechecking. The factories are being established on the side of River especially in Dhaka the first choice of investors is selecting a place by the side of Buriganga River which has made transportation easy to them. Overall the production potentiality of recycled plastic products in Bangladesh is relatively high because of available of factors of production and other resources.

\section{ii. Low Transportation Cost:}

The maximum number of recycling factories has been established in Dhaka on the side of Buriganga River which has made transportation cost very low. Recycling factories easily purchase a large quantity of plastic waste and bring them to their place using river path. According to the owner of recycling factories, it is very cheap and easy for them to bring raw materials by using river path than road.

\subsubsection{Resources}

\section{i. Availability of Raw Materials:}

As Bangladesh is an overpopulated country and plastic products are popular to all class of people, in every minute million of plastic products are being sold and purchased. As a result, plastic wastes are being generated at a large quantity in our country. The main raw material of recycled plastic flakes is used plastic bottles which is very easy to get specially in our country from waste collectors.

ii. Availability of Large and Cheap Labor Forces:

Labor forces are always cheap in Bangladesh because of our dense population and lack of working opportunity. So any labor-intensive industryhas extensive opportunity to start its operation in Bangladesh. In addition recycling plastic does not need high skilled labor. For this reason, it is possible to manage a large number of workers at a low cost.

\subsubsection{Employee Skills and Mix}

\section{i. Lack of knowledge and skill}

Plastic waste can be used to produce different kind of materials through recycling procedure. But in our country plastic recycling companies only produce flakes.. Some medium and large sized companies produce plastic PET straps but the number of this kind of company is very rare and the quantity that they produce is very poor comparing to the demand of foreign buyers. So many foreign buyers are moving to other countries. One of the countries is India.. India is becoming success to produce different kind of products, materials and chemicals from plastic flakes. The demand is so high that they have to import plastic flakes from Bangladesh. Without that, others developed countries like Sweden, Germany are producing power by using plastic waste. Only because of inefficient technology, lack of knowledge and skills, Bangladesh is lagging behind.

\section{ii. Inefficient Labor Force and High Turnover}

The workers who work in recycling factories have no efficiency and skills that they can use in their workforce. They only work to earn. However, the compensation that they are paid is very low, which can motivate them to work from the heart. For this reason, the work turnover rate is high. Without that, having an opportunity in other factories and no requirement of skills, workers can easily switch from one mill to another.

\subsubsection{Capabilities and Core Competencies}

i. Good Quality

Because of having perfect competition among the existing plastic recycling factories, all the factories try their best to maintain good quality. Without that, buyers are also very sensitive at the time of purchasing plastic flakes. They check each sack of plastic flakes, and whether they get any problems in any sack or PVC in plastic flakes, they denied taking order immediately.

ii. Cheap Rate:

Because of having cheap raw materials and inexpensive labor forces, the production cost is low. As a result, the rate of plastic flakes is comparatively low in Bangladesh.

\subsubsection{Research and Development}

\section{i. Lack of research:}

The research and development facility of any industry is essential for creating distinctive features and making a competitive position in the market. Recycling plastic is a growing sector with high possibility in our country, but 
in Bangladesh, no initiatives are observed from public or private sectors. The people who are involved in this sector with the high or medium educational background are not showing more interest to expand this area by introducing new inventions or ideas. In this case, Bangladesh Plastic Goods Manufacturers and Association (BPGMA) can contribute to establishing a new research area to find out how plastic recycling can be an innovative industry in our country.

ii. Lack of High Technology:

Plastic recycling factories use only local machines such as cutter, washer, and dryer to make plastic flakes. Even many factories do not use a washer; they use sunlight to dry plastic flakes and do many tasks manually, which decreases the production efficiency and quality. Where our neighbor country India is making necessary machinery and equipment for the recycling process, whereas Bangladesh does not have own machines to recycle plastic. Technological inefficiency is a major barrier observed in Bangladesh.

\section{iii. Low Tendency for Expansion:}

To start a plastic recycling factory is very easy and inexpensive. It requires only 4-8 lakh takas. Who starts with this small amount, their intention is only to make plastic flakes, not the other products. By making only plastic flakes, it is not possible to think of recycled plastic as one of the export-oriented industries of Bangladesh. Large investors should be attracted to this sector as soon as possible. Governments need to give enough incentives to attract foreign investors in this sector.

\subsubsection{Others}

i. Lack of Good Working Environment:

The recycling factories do not follow environmental law, labor law, and occupation safety law. The working environment is very nasty. Workers do not use masks, gloves, or any other protection to protect them from the unhygienic atmosphere of the factories. As a result, they are getting a different kind of diseases.

\subsection{Recommendations from the Interviewees of Plastic Recycling Factories}

In Bangladesh, plastic recycling factories are still confined in some small and medium-sized mills. It did not get any institutional form. Throughout this research, many important recommendations come from the respondents as their expectations from both the public and private sectors. According to the interviewees, recycled plastic can be a profitable industry if the government can provide all the necessary facilities to the exiting factories and can attract new investors and buyers. Some solicitations come from the people who are engaged in this area for several years are given below;

\subsubsection{Correct Waste Management Procedure}

In Bangladesh, there is no proper waste management system. People throw wastes in any place because of having no idea and awareness about how wastes can be beneficial to the economy. One of the factory owners mentioned that "Proper waste management system is essential for our country, because of incorrect dumping procedure, collection of plastic wastes becomes tough and costly."

\subsubsection{Technological Development}

Technological inefficiency has kept Bangladesh within a small boundary in many sectors. Among them, the waste management industry is a sector in which Bangladesh has huge potentials, but because of poor technology, our country is lagging. Where our neighbor country India has enriched them in the ICT and technology sector and made plastic recycling machinery, here Bangladesh cannot produce export-quality plastic flakes. So the government should immediately focus on technological development in all potential sectors with the thought of doing something new.

\subsubsection{Infrastructure Development}

Poor infrastructure is always a common problem in Bangladesh, which discourages investors. Besides, increasing the price of electricity and water has added a new problem to manufacturing by rising production costs. MD. Nur Islam proprietor of Khaja Engineering Works said that "Rising bill of electricity and water has raised their cost of production."

\subsubsection{Proper Planning}

The absence of proper planning made it difficult to establish recycled plastic as an industry of Bangladesh. It has made it tough to collect wastes from a different area of the country. Since most of the companies in Bangladesh are situated in Dhaka City, city corporations should have proper planning to collect wastes. In this context, two measures can be taken immediately. The first one is based on the market, like changing the structure of 
incentives for collecting wastes where the vendors or street boys who collect plastic waste directly from the garbage can get the incentive. The second one is more important in this regard, those who are manufacturing plastic goods, for whom they are manufacturing and who are consuming should become under a combined structure so that the entire process like collection and recycling can be performed more coordinately. This collection process would become further organized if the different local institutions like City Corporation or municipality can be involved with it. According to the owner of plastic recycling companies, in this way, the percentage of the collection can be upgraded to $80 \%$ to $90 \%$ from $60 \%$, which is at present.

\subsubsection{Financial and Monetary Incentives}

Because of having scarcity of capital and financial incentives, many entrepreneurs do not want to involve in new business operations. Another mill owner mentioned that "It is difficult for us to get loan from banks. If a good system is established to expedite and ease the loan approval process, we can expand our business." Though Bangladesh provides ample incentives for SME entrepreneurs, the government should take targeted incentives to boost the recycled plastic industry.

\subsection{Discussion of Findings}

From the analysis above, it can be concluded that exploring different external factors, Bangladesh has a huge potentiality of the plastics recycling sector in Bangladesh. Instead of having some challenges regarding to customers, suppliers, competitors and other related issues which are elements of the micro environment of an industry, there exists a large scope of this potential for investment in this sector in Bangladesh. On the other hand, macro environmental factors include political, economical, social, technological, environmental and legal factors .All these factors positively support plastic recycling operation in Bangladesh except technological factors where the existing factories are not showing much interest to adopt new technology. Without that the pace of technological development is very low and government could not give attention to it. If both public and private sectors can come forward and take necessary stepsthen the time will be no far when plastic recycling will be a $100 \%$ export oriented industry of Bangladesh and largely contribute to our economy as readymade garment is doing.

Internal Environmental factors include production, resources, employee skills, research and development, core competencies, and internal working environment. All these factors influence the establishment of the recycled plastic industry. Before transforming into an industry, it is important to analyze the internal strength and weaknesses of each existing plastic recycling company. The high potentiality of production, low transportation cost, availability of raw materials, and cheap labor forces, core competencies in quality, cheap rate of products have made the plastic recycling sector more attractive. On the other hand, lack of research, scarcity of high technology, the low tendency for expansion, and lack of a good working environment have created a lot of challenges to compete with international competitors. If the government can help to remove all these barriers and effective initiatives can be taken by both public and private sectors then all these barriers can be overcome. In short, the most important thing is proper observation, which can make the plastic recycling industry a glorious industry in Bangladesh.

\section{Conclusion}

In summary, this study finds that plastic recycling is a process that can contribute to both the economy and the environment of a country. It is a great system to manage plastic wastes in a way that can be used to produce different kinds of valuable products. High production potentiality, low production cost, availability of cheap labor and raw materials, high demand for Bangladeshi plastic flakes in the international market have made the sector more attractive.

Successful examples of countries, such as India, Sweden, Germany, the UK, Switzerland, the USA, and many other developed and developing countries, are making use of high technologies to produce different types of products by using recycled plastic. Bangladesh can follow these countries to make the best use of their resources. Lack of technological inventions, proper education, lack of awareness, knowledge, and skill at different phases of the recycling plastic makes it challenging for this industry to operate and grow effectively. Analysis of the critical barriers reveals that lack of a proper waste management system, proper planning, infrastructural and technological development, financial and monetary incentives are the major constraints to extract the full potential of the recycled plastic industry in Bangladesh.

The discussion reveals that plastic waste can be transformed into a good source of export income for the country, but the lack of awareness among Bangladeshi people poses a huge challenge for the industry to expand. Therefore, regular awareness programs should be established at the community level to create public awareness 
and knowledge. Both the public and private sectors should focus on the efficient waste management system. The government can also take initiatives to increase community awareness about the use of plastic waste and take necessary steps to establish a strong system to collect and process it at minimum cost. Without that, coordination is necessary among the plastic waste collectors, recycling operators and buyers. For proper waste management system, plastic industries need to take some special measures. The coordinated efforts of the Government, Consumers, Recycling Industries and Plastic product manufacturers could create a positive environment for recycled plastic products and companies. Through this way the plastic waste management would emerge as a major productive industry of Bangladesh.

This research report on the potentiality of recycled plastic as a profitable industry and major export-oriented product can assist to the academic researchers to make further analysis on the related topic. This study can help the policy makers who are concerned about making proper waste management policies. It can also help to the people who are concerned about the environmental pollution and are also finding the way to protect environment from plastic pollution. Without that, from this study, the entrepreneurs who are searching a growing and profitable sector for their investment can get idea about the potentiality of recycled plastic as a profitable sector in Bangladesh.

Recycled plastic is a growing sector. Different kinds of analysis are necessary for our country to search the possibility and contribution of it. This study has only focused on the potentiality of recycled plastic as an industry and export-oriented product in Bangladesh based on descriptive analysis but does not provide any statistical interpretation about the contribution of recycled plastic on the economy of Bangladesh. There are also many areas where different research regarding the recycled plastic can be taken. For example, researchers who are concerned about plastic recycling sector can make a statistical analysis to find out how much recycled plastic has contributed or can contribute in our GDP or a comparable analysis among several years about the contribution of recycled plastic to economy of Bangladesh. Without that, researchers can also pursue their analysis about the importance of recycled plastic products as consumable goods in Bangladesh, or the diversification of recycled plastic products with technological development in future and so on. But instead of some lacking, researchers can use this study as a base for their further analysis.

\section{References}

Ahmed, S. (2019, January 2). Plastic exports maintain rising trend. The Independent. Retrieved from http://www.theindependentbd.com/post/181467

Ayan, A. J. (2018, July 20). Turning Plastic Wastes to Resources. The Daily Star. Retrieved from https://www. thedailystar.net/environment/turning-plastic-wastes-resources-curbing-pollution-profitably-1608376

Brinkmann, S., \& Kvale, S. (2015). Interviews: learning the craft of qualitative research interviewing (3rd ed.). Sage Publications.

Creswell, J. W. (2014). Research Design: Qualitative, Quantitative \& Mixed Methods Approaches (4th ed.). Sage Publication.

Hopewell, J., Dvorak, R., \& Kosior, E. (2009). Plastics recycling: challenges and opportunities. The Royal Society, 2115-2126. Retrieved from https://www.ncbi.nlm.nih.gov/pmc/articles/PMC2873020/pdf/rstb2008 0311.pdf

Hossain, P. M. N. (2016). The Prospects and Challenges of Plastic Industries in Bangladesh (p. 19). Retrieved from https://www.theseus.fi/bitstream/handle/10024/105774/Thesis.pdf?sequence/

Islam, M. S. (2011). Prospects and Challenges of Plastic Industries in Bangladesh. Journal of Chemical Engineering, ChE. 26(1), 16-21. Retrieved from file://C:/Users/USER/Downloads/10176-Article\%20Text37504-1-10-20120324\%20(11).pdf

Leblanc, R. (2019, June 25). An Introduction to Plastic Recycling and the Plastic Recycling Process. Retrieved from https://www.thebalancesmb.com/an-overview-of-plastic-recycling-4018761

OECD. (2018). Improving Plastics Management: Trends, policy responses, and the role of international co-operation and trade. OECD Environment Policy Papers, No. 12, OECD Publishing, Paris. https://doi.org/10.1787/c5f7c448-en.

Ritchie, H., \& Roser, M. (2018, September 1). Plastic Pollution. Retrieved from https://ourworldindata.org/plastic-pollution\#citation

RMG Bangladesh. (2019). Export of plastic goods up 18.34pc. Retrieved from https://rmgbd.net/2019/05/export-of-plastic-goods-up-18-34pc/ 
Shimo, M. H. U. (2014). Plastic Recycling in Bangladesh, What needs to be done? (pp. 31-39). Retrieved from https://core.ac.uk/download/pdf/38116820.pdf

Sultana, N. (2019). Plastic Recycling in Bangladesh. Advance in Environmental Waste Management \& Recycling, 2(1), $1-4$. $\quad$ Retrieved from https://opastonline.com/wp-content/uploads/2019/01/plastic-recycling-in-bangladesh-aewmr-19.pdf

The Association of Plastic Recyclers, \& American Chemistry Council. (2018). 2017 United States National Postconsumer Plastic Bottle Recycling Report (28th). Retrieved from https://plastics.americanchemistry. com/Reports-and-Publications/National-Post-Consumer-Plastics-Bottle-Recycling-Report.pdf

The Financial Express. (2018, October 3). Export Potential of Recycled Poly-Chips. The Financial Express. Retrieved from https://www.thefinancialexpress.com.bd/editorial/export-potential-of-recycled-poly-chips1538580672

\section{Copyrights}

Copyright for this article is retained by the author(s), with first publication rights granted to the journal.

This is an open-access article distributed under the terms and conditions of the Creative Commons Attribution license (http://creativecommons.org/licenses/by/4.0/). 